\title{
Gene therapy's other investment window
}

The first public European gene therapy company will be Oxford Biomedica (Oxford, UK). That became almost certain in midSeptember, when the company announced it had attracted $£ 750,000$ ( $\$ 1.2$ million) through a private placement involving, among others, Brian Richards and Alan Goodman, who have been behind several other UK biotechnology companies. Interestingly, Oxford Biomedica will wait only weeks before going public in late October or early November on London's Alternative Investment Market (AIM).

More established European gene therapy companies have hesitated-or have had to hesitate-before jumping toward public finance. Therexsys (Keele, UK), for instance,

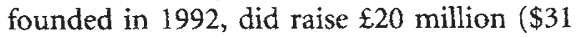
million) in private financing in May and plans to go public only in 1997. Transgène (Strasbourg, France) also plans an offering but is less clear about when.

Oxford Biomedica, which has just six patent applications covering combined non-viral and retroviral delivery systems, adaptor molecules for targeted delivery, and vector manipulation systems, is looking for $\mathfrak{E} 5$ million ( $\$ 7.8$ million) right away. But the company has no granted patents, no clinical trials, and no facilities. Will this offering be simple opportunism on the part of the founding investors, or is there a specific and different financing window opening for gene therapy companies?
Conditions for biotechnology offerings have recently been sufficiently adverse that companies such as Immune Response (Carlsbad, CA), Cell Therapeutics (Seattle, WA), Aviron (Mountain View, CA), NexStar (Boulder, CO), Matritech (Cambridge, MA), and Cambrio (Cambridge, UK) have postponed or withdrawn initial or follow-on

\section{Is there a specific and different financing window opening for gene therapy companies?}

offerings in July and August. However, in this same period, there has been a rash of gene therapy company offerings: Transkaryotic Therapies (Cambridge, MA) filed in late August for an offering worth $\$ 32.5$ million, while Introgen Therapeutics (Austin, TX) sought to raise $\$ 32$ million in early September. Ingenex (Menlo Park, CA) hopes to raise $\$ 15.7$ million in its IPO filed in July, which has not yet closed. Recently, Targeted Genetics (Seattle, WA) completed a follow-on share offering in June, raising $\$ 14$ million.

These launches have occurred, however, at a time when the stock market is "fiercely undervaluing" gene therapy companies, according to John Savin, biotechnology analyst with Grieg Middleton (London). Elizabeth Silverman, a biotechnology analyst at Punk, Ziegell, and Knoell (New York) points out, too, that in the biotechnology downturn of July and August, gene therapy companies suffered disproportionately. "They are perceived as early stage and lacking sound clinical results. Gene therapy companies generally underperform," she said.

During biotechnology's surge between July 1995 and July 1996, three gene therapy companies did make successful outings: GeneMedicine (The Woodlands, TX) in October 1995, Avigen (Alameda, CA) in May 1996, and Atlantic Pharmaceuticals (Northbrook, IL) in December 1995. However, gene therapy companies stock generally underperformed the wider biotechnology sector by approximately $20 \%$ during biotechnology's boom period. That may have reflected the continuing pessimism that followed gene therapy's initial money raising surge in 1994.

Part of gene therapy's problem has been that investors may be looking for companies with more tangible assets. "The stock market is not terribly appreciative of pure technology stocks," says Grieg Middleton's Savin. They don't come much purer than Oxford Biomedica.

Emma Johnson

\section{Can ReoPro repolish tarnished monoclonal therapeutics?}

Centocor (Malvern, PA) released completed data from the EPIC, EPILOG, and CAPTURE trials, all of which evaluated the efficacy of the platelet-binding monoclonal antibody drug ReoPro in preventing complications of angioplasty. Good news too for heart patients-ReoPro reduced the risk of death, heart attack, and the need for repeat angioplasty by nearly $60 \%$ one month after treatment, and a significant risk reduction persists for at least three years. Good

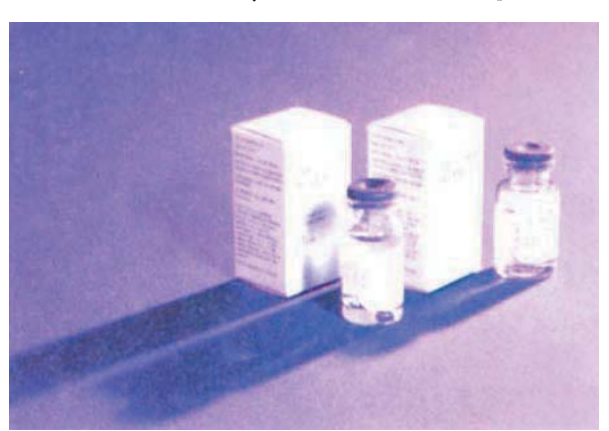

Casting a long shadow? Centocor's monoclonal antibody ReoPro. assessment study concluded that ReoPro recoups most of its cost within six months in high-risk patients undergoing angioplasty.

Reflecting on the current age of managed care and health econom-ics, "you definitely need more data, and data that speaks to longterm outcomes in order to gain acceptance and penetration of the product," observes Centocor president and CEO David Holveck. The three trials combined followed news for Centocor and the industry-as ReoPro proves not only its therapeutic value, but also its economic worth. A cost more than 6000 patients. An economic assessment of the initial EPIC trial found that while ReoPro treatment cost $\$ 1407$ per patient, after 6 months the mean savings in medical costs for ReoPro-treated patients was $\$ 1270$, for a net incremental cost of $\$ 293$ (Circulation 1996, 94:629-635). Data such as these have become essential for combating economic resistance to new, high-cost technology in the healthcare market.

ReoPro has gained relatively rapid acceptance since it became the first US Food and Drug Administration (FDA, Rockville, MD)approved monoclonal antibody drug in December 1994. Holveck anticipates that ReoPro can penetrate $50-60 \%$ of the angioplasty market by the end of this year. During the past 12 months, ReoPro sales in the US and Europe have risen from $\$ 6.5$ million in $3 Q 95$, to $\$ 12.3$ million in $4 Q 95, \$ 22.8$ million in $1 Q 96$, and $\$ 37.2$ million in $2 Q 96$. By the fourth quarter of this year, Eli Lilly (Indianapolis, IN), which markets ReoPro in the US and Europe, could realize sales of $\$ 53$ million. Long-term analyst's projections fore- 